Revista Iberoamericana, Vol. LXXVIII, Núms. 238-239, Enero-Junio 2012, 329-348

\title{
TECNOCIENCIA Y CIBERCULTURA EN MÉXICO: HACKERS EN EL CUENTO CYBERPUNK MEXICANO ${ }^{1}$
}

POR

\author{
Hernán Manuel García
}

Wayne State University

$<$ LOTek $>$ in the coming elections several parties want to hire us and other hackers too $<$ ilich> tell me about it.... sounds interesting.... $<$ LOTek> pan, prd, pri they want to derange their information centers on the 2nd of july

$<$ ilich $>$ and what do they offer and ask for exactly? $<$ LOTek $>$ they offer \$\$ \& information benefits that only political parties have access to like the election database, in fact I have part of the database somewhere around here $<$ ilich $>$ is the government ready this time to manipulate numbers? I mean technically... $<$ LOTek> yeah, as usual. The 3 main political parties are trying to hire hackers. which might mean they truly need help, but who knows? Maybe the pri is only doing it as a cover. Some others already have hackers working, like the pan $<$ ilich> and what have you thought about it? $<$ LOTek $>$ we arent on the side of politics $<$ ilich> $i$ mean, $i$ would have given it a thought... $<$ LOTek> yeah, but its dangerous, too dangerous. If we get to fuck up something of the ife they surely wouldn't want any witnesses

Hackers Chat

Esta conversación se llevó a cabo en el marco de una entrevista que realizó el 15 de enero del 2000 -en algún chat del cyberspacio- el escritor y cineasta tijuanense Fran Ilich a L0Tek, uno de los miembros del afamado colectivo de hackers mexicanos denominado X-ploit que dos años antes había adquirido notoriedad internacional por sus

\footnotetext{
1. Quiero agradecer infinitamente a Gabriel Trujillo Muñoz y a Miguel Ángel Fernández su servicial y amable ayuda para localizar y hacerme llegar textos imposibles de conseguir. Sin su ayuda la investigación hubiera sido incompleta.
} 
acciones de hacktivismo, ${ }^{2}$ infiltración y hackeo dirigido a varias páginas electrónicas de dependencias gubernamentales a nivel federal en México. La actividad del underground mexicano, como se le conoce a la comunidad hacker en México, empezó a consolidarse de forma paralela al conflicto en Chiapas y no fue indiferente a lo que ocurría en el sur del país. ${ }^{3}$ Jorge Alberto Lizama estima que "a partir de 1994 el escenario del hacktivismo experimentó en México uno de los puntos más álgidos de su historia cuando el Ejercito Zapatista de Liberación Nacional (EZLN) se sirvió en gran medida de Internet para dar a conocer al mundo el levantamiento armado y las demandas sociales de los indígenas chiapanecos” (“El poder” 14). Poco tiempo después el EZLN empezó a gestar vínculos sociales con grupos de izquierda que utilizaban estratégicamente tecnologías de la información y comunicación (Association for Progressive Communications), artistas digitales (The Electronic Disturbance Theater) y activitas en red (Peace Net) (16). Estos grupos no sólo dieron al EZLN las primeras estrategias de comunicación y hacktivismo a nivel digital, sino que además sirvieron como punta de lanza para emprender acciones de contra-información y de desobediencia electrónica ante la información pasterizada, sobre el conflicto en la selva Lacandona, emanada de los medios masivos de comunicación y de los boletines informativos oficiales del Gobierno mexicano durante el sexenio del presidente Ernesto Zedillo (1994-2000) (4).

De 1994 a 1998 se consolidó aun más la red social-electrónica del EZLN al sumar dentro de sus filas a algunos de los grupos hacktivistas más importantes de la época como: Strano Network (Italia), Electronic Disturbance Theater (Nueva York) y X-ploit (México) ${ }^{4}$ que mediante diferentes técnicas organizaron manifestaciones activistas desde

2 El término de hacktivismo se compone de los vocablos hack y activismo y se refiere a una manifestación estratégicamente organizada y llevada a cabo por un grupo o red social en el ciberespacio. Para más información sobre el hacktivismo se puede consultar Networks and Netwars: The Future of Terror, Crime, and Militancy (2001) y Future Active: Media Activism and Internet (2002).

3 Thea Pitman en su artículo "Latin American Cyberprotest: Before and After the Zapatistas" ofrece un recuento completo de cómo el EZLN pasó del levantamiento armado a lucha virtual en el ciberespacio por medio de las recomendaciones y sugerencias de grupos activistas en red internacionales. Sin embargo, la investigadora inglesa en ningún momento hace referencia de la participación del colectivo hacker mexicano X-ploit en dicho viraje tomado por el EZLN.

4 Alberto Lizama explica que en la actualidad el estudio del mundo underground hacker mexicano es problemático ya que este movimiento contracultural fue absorbido por la industria cultural y lo convirtió en una moda popular. Lizama explica que "es precisamente esta ambigüedad entre los hackers auténticos y los artificiales, la que dificulta abordar el estado del arte de los hackers en México" ("Hackers"). Sin embargo, en su artículo, además de X-ploit, sí identifica a otros dos colectivos de hackers mexicanos comprometidos con diferentes propósitos: 1) Mexican Hackers Mafia (MHM), que se dedican al phone hacking o phreaking. Este colectivo se caracteriza por elaborar información detallada del estado actual de las comunicaciones en México, así como evaluar y criticar la forma en que las compañías como Telmex ofertan el servicio a sus usuarios. Igualmente MHM incluye diagramas para "mejorar" el servicio de los teléfonos celulares y tarjetas telefónicas a partir de instrucciones técnicas que proporcionan.

Revista Iberoamericana, Vol. LXXVIII, Núms. 238-239, Enero-Junio 2012, $329-348$
ISSN 0034-9631 (Impreso) 
la red en nombre del EZLN (16). La acción hacktivista más impactante, en términos de comunicación política contracultural en México, fue llevada a cabo por el colectivo hacker mexicano X-Ploit que durante 1998 comenzó a practicar el defacement web contra páginas electrónicas de dependencias federales del gobierno mexicano (17-18) como la Secretaría de Hacienda y Crédito Público (febrero de 1998), la Comisión Nacional del Agua (abril de 1998), el Instituto Nacional de Estadística, Geografía e Informática (abril de 1998), el Senado de la República (mayo de 1998) y la Secretaría de Salud (julio de 1998).

La conversación que abre este trabajo y lo dicho hasta ahora pone en evidencia que en México existía una comunidad hacker integrada al desarrollo técnico y al quehacer político mexicano como ejercicio y responsabilidad civil de la ciudadanía joven del país. Sin embargo, por otra parte, la conversación entre Ilich y L0Tek también deja entrever cómo grupos políticos buscaban a toda costa consolidarse en el poder hasta al grado de corromper el joven espíritu hacker al intentar privatizar su conocimiento y su ética al absorberlos dentro del enmarañado sistema corporativo y corrupto de la política mexicana. Los efectos de la incorporación de la cultura hacker al modus operandi del sistema es uno de los temas que ha sido desarrollado en buena medida por la cuentística de ciencia-ficción mexicana a través del subgénero del cyberpunk. ${ }^{6}$

2) Raza Mexicana, que por medio de su revista electrónica, de mismo nombre, se dedica a tratar de "limpiar" el concepto de hacker. Este grupo no politizado se dedica a la divulgación de la informática, a la investigación para mejorar sistemas o programas, a la solución de problemas técnicos y al diseño de programas originales ("Hackers”).

5 El defacement web consiste en ingresar a una página web para ponerla fuera de servicio y a la vez modificar y/o alterar su contenido original en señal de protesta. Esta práctica requiere habilidades técnicas para romper con el sistema de seguridad de la página y así modificar su información. Esto hace que el administrador de la página quede en evidencia por no poderla proteger adecuadamente. Igualmente el defacement web como estrategia hacktivista tiene el propósito de bloquear y entorpecer la información y los canales electrónicos de difusión como si se tratara del bloqueo de una calle como señal de manifestación. Para ver un defacement típico del grupo X-ploid consultar la página: <http:// www.2600.com/hackedphiles/sanpedro/hacked/>.

6 El prefijo cyber se popularizó en Estados Unidos a finales de la década de los ochenta y dio paso a el establecimiento de vocablos, ahora muy de moda, como cyberpunk, cyberspace, cyberculture, entre otros. De manera más exacta, el término cyber se deriva del concepto cybernetics acuñado en 1940 por el científico Norbert Wiener, quien en su libro The Human Use of Human Beings: Cybernetics and Society definió el vocablo como "new theory of messages" que incluía "[the] means of controlling machinery and society, the development of computing machines and other such automata, certain reflections upon psychology and the nervous system, and a tentative new theory of scientific method" (citado por Heuser 20). En cuanto al vocablo punk, éste se utilizó para asignarle al movimiento un grado de actitud rebelde y de subcultura, rasgo tomado del estilo musical punk surgido a finales de los años setenta que llevaba como estandarte el eslogan de "no future" de la banda punk inglesa Sex Pistols (Heuser 33). De esta forma, varios historiadores del cyberpunk concuerdan en establecer que el género es una amalgama entre los conceptos de high technology y low life (Yehya 3, Kellner 303, Heuser xviii).

Revista Iberoamericana, Vol. LXXVIII, Núms. 238-239,
ISSN 0034-9631 (Impreso) 
Esta expresión de la CF se convirtió en México, a mediados de los años noventa, en punta de lanza de la renovación de la CF mexicana, así como en uno de los intentos más radicales de re-configuración del quehacer literario nacional. Desde diversas temáticas, el cyberpunk mexicano articula nuevas identidades contraculturales con el objetivo de observar y criticar la mediación tecnológica introducida al país a partir de la introducción del neoliberalismo y la globalización. El presente trabajo propone ofrecer una lectura en torno al cyberpunk en dónde se observará cómo este subgénero de la CF cuestiona los paradigmas nacionales que supuestamente colocaban a México como una nación desarrollada, moderna y tecnológicamente preparada para entrar al siglo xxi.

Gabriel Trujillo Muñoz (1958) a manera de reclamo hace notar que "[a] partir de 1991 comienza a circular en México el primer tomo de la antología que hoy es, para los enterados, un hito histórico en la literatura nacional” ("Futuro bajo palabra” 44). Esta antología, a su juicio, rompe con las barreras del "ninguneo" de la crítica literaria para poner sobreaviso que algo nuevo está a punto de emerger (44). La antología referida por Gabriel Trujillo Muñoz es, ni más ni menos, Más allá de lo imaginado (tres tomos: 1991, 1991 y 1994) en donde Federico Schaffler (1959) recopila la CF escrita por una promoción de escritores mexicanos que se habían dado a conocer gracias al Premio Nacional Puebla de CF impulsado por Celine Armenta con el apoyo del Consejo Nacional de Ciencia y Tecnología (CONACYT).

El Premio Puebla de Ciencia-Ficción marcó un parte aguas en la difusión y promoción de la CF en México ya que el género, durante largo tiempo, había quedado fuera del mapa de la literatura nacional. Gracias al "Premio Puebla", los escritores mexicanos que pensaban que cultivaban la CF en la soledad se dieron cuenta de que no se encontraban solos en su lucha por mantener este género literario en la república de las letras (Trujillo Muñoz, “El futuro” 25). José Luis Zárate (1966) evaluando la importancia del Premio Puebla para el desarrollo de la CF mexicana opina que:

\begin{abstract}
En realidad todo empezó en 1984: se organizó el primer concurso nacional de cuento de ciencia-ficción, por una revista de divulgación científica, y fue a partir de ese concurso que ha renacido la ciencia-ficción. Siempre ha existido la ciencia-ficción en México, pero muy subterránea, nadie conocía a nadie. Había escritores que aparecían y desaparecían y nadie se enteraba de su existencia porque en México es muy difícil la distribución a nivel nacional. Por lo tanto, si en una provincia se publicaba una revista, en la otra no se sabía nada. (citado por Trujillo Muñoz, Los confines 186)
\end{abstract}

Gracias a este concurso se obtuvo un resultado inmediato que consistió en la difusión a nivel nacional de la CF ya que se consiguió la publicación continua de los cuentos ganadores y los cuentos con menciones honoríficas en la revista del CONACYT: Ciencia y desarrollo. Lo anterior permitiría romper con el estado de "clandestinidad" en el que permanecía el grupo. De esta forma, el Premio Puebla permitió que la comunidad de

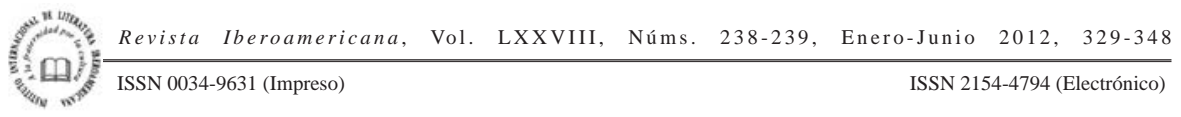


escritores de CF creciera aun más hasta convertirse, según Trujillo Muñoz, en una legión que fue descubriendo que "sus participantes se hallaban diseminados a lo largo y ancho del territorio nacional” (El futuro 25).

Federico Schaffler explica en la introducción de Más allá de lo imaginado I que su antología "pretende ser una muestra representativa de los mejores autores de cienciaficción mexicana de los últimos años" (19), así como una "ruptura del género contra el encajonamiento en el que se [había] envuelto” (20). Como resultado, Más allá de lo imaginado, según Schaffler, "es la primera antología nacional seria y contemporánea de ciencia-ficción, con cuentos de calidad y representatividad de diversos lugares del país" (20-21). ${ }^{7}$

En los tres tomos de Más allá de lo imaginado, publicados entre 1991 y 1994, converge una gran variedad de temáticas presentadas a través de diferentes subgéneros de la CF. Uno de estos subgéneros que surgió y logró convertirse en todo un movimiento literario en México fue el cyberpunk. ${ }^{8}$ En México la primera publicación cyberpunk fue el cuento “La red”, de Isidro Ávila (1974), que apareció en el primer volumen de Más allá de lo imaginado. Después, el género empezó a tomar forma con las publicaciones de los artículos de tipo manifiesto "Cyberpunk, ciencia-ficción y thriller” (1993) y "El cyberpunk” (1997), de Gerardo Porcayo (1966), y la circulación de la primera novela cyberpunk a nivel Latinoamérica, La primera calle de la soledad (1993), del mismo Porcayo. Sin embargo, se habla de un movimiento cyberpunk ya establecido y visible hasta 1997 con la publicación de la antología Silicio en la memoria, en donde Gerardo

7 Schaffler hace explícita la deuda con el Consejo Nacional de Cuento de Ciencia-Ficción Puebla que sirvió como punto de partida para iniciar la rigurosa selección de los cuentos a incluir en el proyecto. Al respecto, Schaffler comenta que desde la aparición del concurso (1984 a la fecha de la aparición del primer tomo de la antología 1991), “este concurso ha generado una participación de entre 130 a 150 cuentos por año, de los cuales, un mínimo de 10 por ciento es bueno” (Más allá I:21). De esta forma, Más allá de lo imaginado I es una muestra de la mejor expresión temática y estilística del cuento de CF mexicana a finales de siglo xx. Los autores publicados en la primera entrega fueron: Juan Armenta Camacho, Adriana Rojas Córdoba, Mauricio-José Schwarz, Arturo Arredondo, Gabriel Trujillo Muñoz, Guillermo Faber, Gerardo Horacio Porcayo, Rodrigo Madrazo, Juan José Morales, Gabriela Rábago Palafox, Irving Roffé, Arturo César Rojas y Federico Schaffler. Es importante recalcar que el primer tomo de la antología se imprimió en enero de 1991, el segundo en febrero del mismo año y el tercer volumen vio la luz hasta junio de 1994. Miguel Ángel Fernández afirma que hay material suficiente para publicar Más allá de lo imaginado IV y Más allá de lo imaginado $V$ y propone que la serie de antologías Más allá de lo imaginado continúe indefinidamente bajo los mismos criterios editoriales; si no se consigue disfrutando del apoyo del Consejo Nacional para la Cultura y las Artes, propone que se publique bajo el sello de otra casa editorial ya que "al fin y al cabo sus ventas y su éxito ya están garantizados" ("Más allá”).

8 El origen del cyberpunk se sitúa alrededor de 1982 y fue bautizado por el editor de CF Gardner Dozois, quien lo utilizó para referirse a la prosa de William Gibson, autor de la novela Neuromancer (1984), obra pionera del género que describe un mundo regido por corporaciones japonesas en donde un hacker, quirúrgicamente tecnificado, se ve envuelto en una telaraña de espionaje industrial debido al tráfico de información y software (Yehya 6-8).

Revista Iberoamericana, Vol. LXXVIII, Núms. 238-239, Enero-Junio 2012, 329-348
ISSN 2154-4794 (Electrónico) 
Porcayo reúne a un grupo de once autores representantes del género. En la introducción, Porcayo destaca que su antología representa:

once historias que exploran el actual estado de la cultura y la sociedad, el enfrentamiento de las nuevas generaciones a las ráfagas de los mass media, los oscuros y omnipresentes laberintos de la internet [...] once historias que solo caben dentro de un género, que sólo a través de éste pueden ser abordadas: el cyberpunk. (4)

Debe destacarse que el giro dado por la CF mexicana en los noventa, y que los Estados Unidos había explotado comercialmente desde la publicación de Neuromancer, ya había iniciado en los cuentos "Sueño eléctrico” (1984), de Gerardo H. Porcayo; “Una noche”, de Miguel Ángel Gutiérrez (1985), “Análogos y therblings” (1986), de José Luis Zárate; y "El velero azul”, de Rodrigo Madrazo (1988). De hecho, hay autores que no conocían la obra de William Gibson y que pensaban que ya hacían cyberpunk antes que el autor norteamericano. José Luis Ramírez (1974) documenta este hecho que tiene mucho que decir del periodo histórico en el que se enmarca el cyberpunk mexicano. Ramírez dice:

Eso nos pasó a muchos. Aunque pienso que no se trataba de que ya escribiéramos cyberpunk, de hecho, supongo que sucedió lo siguiente: nosotros abordamos el presente del México de los noventa -crisis económica, globalización, revolución, violencia urbana, narcotráfico, internet, apertura comercial, la estúpida creencia de que habíamos dejado el tercer mundo y estábamos a punto de pertenecer al primero- y ese presente, es el mismo que los escritores etiquetados cyberpunk en los Estados Unidos, vivieron diez años antes. A falta de una etiqueta mejor, también en México se denominó a la nueva corriente: cyberpunk. (“Cyberpunk”)

La gran mayoría de los cuentos cyberpunk se enmarcan dentro de un futuro cercano en donde se hace evidente una atmósfera "pos-global”. En la representación de este clima el estado ha sucumbido debido a la estrepitosa caída de la economía global, el grueso de la población subsiste paupérrimamente a causa de los altos índices de desempleo y las corporaciones transnacionales han ascendido al poder como fortalecidos sobrevivientes del fracaso del sistemaneoliberal. Las representaciones más recurrentes de lo "pos-global" que los cuentos presentan son: imágenes de tribus "pos-urbanas", drogas tecnificadas, edificios abandonados y vandalizados, territorios dominados por bandas, discotecas de ambiente negro enclavadas en un más oscuro barrio, mercenarios con prótesis letales, descomunales fiestas de hackers, prostitutas de carnes flácidas que compiten contra irresistibles virtual girls, y el entorno de la realidad virtual como vía de perdición.

Así mismo, la cuentística cyberpunk representa a la juventud mexicana desde diferentes ángulos, pero sobresale la caracterización de los jóvenes comúnmente como hackers a sueldo, como obreros automatizados, como consumidores de drogas

Revista Iberoamericana, Vol. LXXVIII, Núms. 238-239, Enero-Junio 2012, $329-348$
ISSN 0034-9631 (Impreso) 
electrónicas, como letales cyborgs mercenarios, como miembros de peligrosas tribus urbanas y como simples obreros tecnificados al servicio de una corporación. Igualmente, estos cuentos alimentan su cuadro de referencia alrededor del recrudecimiento de los efectos de la globalización a finales de siglo xx. El contexto de vida para los jóvenes en el cuento cyberpunk se ve abrumado por una crisis económica prolongada que ha causado la pobreza extrema y la nula movilidad social. Igualmente, las atmósferas de los cuentos sugieren que los proyectos de vida de los jóvenes se han nulificado a consecuencia del desempleo y la debacle de las instituciones. Por esta razón, en la mayoría de los cuentos los jóvenes son víctimas y presas de la delincuencia organizada y de las corporaciones transnacionales que los utilizan como materia prima para lograr consolidar sus imperios de poder.

Por lo consiguiente, los jóvenes dentro de la narrativa hacker distan, en gran medida, de formar parte de una comunidad que produzca y comparta información a través del conocimiento tecnológico ya que sus redes sociales de cooperación y difusión han sido desmanteladas o controladas. De esta forma, en el cyberpunk los hackers no representan una fuente cultural de innovación tecnológica e informática que abra paso al desarrollo de una sociedad red como lo plantea Manuel Castells, sino que la representación del hacker es la de un joven convertido en obrero que trabaja bajo un fuerte dispositivo de seguridad al estilo corporativo. ${ }^{9}$ De forma similar, otros cuentos denuncian cómo los hackers son obligados a participar de forma obligada dentro de los contornos de la economía informal o la delincuencia organizada.

Bajo este enfoque, el cyberpunk en México se puede dividir en seis áreas temáticas principales las cuales, en mayor o menor grado, se encuentran presentes en casi todos los relatos bajo diferentes modalidades o acercamientos. Así, la cuentística cyberpunk mexicana se puede organizar en torno a los siguientes temas: A) Relatos que denuncian las formas de control y represión contra individuos que debido a sus destrezas técnicas en sistemas de computación pudieran desestabilizar un orden de control establecido. A través de esta temática adquiere un papel importante la figura del hacker. ${ }^{10} \mathrm{~B}$ ) Cuentos

9 Manuel Castells desarrolla su concepto de "la sociedad red" en su magna obra de tres volúmenes: The Information Age: Economy, Society and Culture, Volume 1: The Rise of the Network Society (1996), The Information Age: Economy, Society and Culture, Volume 2: The Power of Identity (1997) y The Information Age: Economy, Society and Culture: Volume 3: End of Millennium (1998). Para consultar una versión resumida de las ideas principales de The Information Age que le dan forma al concepto de "sociedad red" consultar el artículo "Informacionalismo y sociedad red" de Manuel Castells que aparece en la bibliografía del presente trabajo.

${ }^{10}$ Los relatos principales bajo esta temática son: "El trozo más grande” y "El último de los hackers", de Bernardo Fernández (1972); “Hielo”, de José Luis Ramírez; "Persiana de piel”, de Gerardo Sifuentes; "Buscando”, de Ricardo Guzmán Wolffer (1966); “Imágenes rotas, sueños de herrumbre”, de Gerardo Horacio Porcado; "Dos días de permiso”, de José Luis Ramírez (1974); y "El navegante”, de Rodrigo Pardo (1975).

Revista Iberoamericana, Vol. LXXVIII, Núms. 238-239, Enero-Junio 2012, $329-348$
ISSN 0034-9631 (Impreso) 
que proyectan imágenes de caos y descontrol social a causa de la implementación de un fuerte aparato de represión impuesto por un estado de ultra-derecha o por corporaciones transnacionales que han asumido el control total de la población. ${ }^{11} \mathrm{C}$ ) Cuentos que establecen una narrativa del trabajo tecnificado en donde se advierte cómo el individuo es intervenido quirúrgicamente para que desempeñe su trabajo de forma eficiente. En este sentido, estos relatos exaltan cómo las corporaciones y las maquiladoras adquieren protagonismo escalofriante al convertir a sus trabajadores en cyborgs. $\left.{ }^{12} \mathrm{D}\right)$ Relatos que funcionan como testimonios sociológicos de las tensiones y conflictos creados por las tecnologías de la información y comunicación como servicio proporcionado por corporaciones. Estos cuentos hacen hincapié en las implicaciones y las consecuencias de sumergirse en el ciberespacio como forma de abyección, doble vida o placer. ${ }^{13} \mathrm{E}$ ) Relatos en donde la realidad virtual se utiliza con fines psiquiátricos como estrategia de ortopedia social. Este formato del cyberpunk advierte que la realidad virtual es utilizada por corporaciones, instituciones de salud mental y agencias policíacas con el fin de tratar patologías, formatear mentes de criminales o mantener en estado vegetativo a disidentes políticos y enfermos terminales. ${ }^{14}$ F) Narraciones que proponen -desde un estado de caos, incertidumbre y desilusión- una estética de la esperanza. Bajo esta propuesta los cuentos proclaman la posibilidad de una reestructuración social y cultural a través del arte, la asimilación individual y la revolución. ${ }^{15}$

Dentro de la narrativa hacker destaca el cuento "El trozo más grande”, de Bernardo Fernández (también conocido como BEF). A través de la narración se puede intuir que el planteamiento que realiza el relato en torno a la emergencia de la subcultura hacker se enmarca de forma paralela a la integración y apertura de México a la agenda neoliberal

${ }^{11}$ Bajo esta variante reciben importancia la representación de grupos marginales en: "Sólo se recuerda el primero”, de Bernardo Fernández; “Santo Sudario”, de José Luis Ramírez; “Ciudad perdida”, de Caín Kuri Sánchez (1976); “Hyperia”, de José Luis Zárate; “Panchito’s story”, de Jorge Chípuli (1976); y “Conversaciones con Joni Rei”, de Pepe Rojo (1968).

${ }^{12}$ En este formato se inscriben los relatos: “Análogos y Therblings”, de José Luis Zárate; "Para Skim” y "Ruido gris”, de Pepe Rojo; “Llegar a la orilla”, de Guillermo Lavín (1952); “Tajamar neutral”, de Carlos Alberto Limón (1972); “(e)”, de Bernardo Fernández y Gerardo Sifuentes; “Ciudad perdida”, de Caín Kuri Sánchez; “Cenizas de fractal”, de Jorge Eduardo Álvarez (1968); y "La noche del cazador”, de Alejandro Melchor (1973).

13 “Mercurio rojo”, de Caín Kuri Sánchez; "El despertar”, de Rodrigo Pardo; “La red”, de Isidro Ávila; “El epílogo de Alicia” y "Cybersexo”, de Gerardo Sifuentes; “Cajas chinas”, de José Luis Zárate; "Virtual realidad”, de Andrés González; y "Los crímenes que conmovieron al mundo”, de José Luis Velarde (1956), son los relatos pertenecientes a esta visión.

${ }^{14}$ Entre los cuentos que develan esta preocupación se pueden mencionar: "Wonderama”, de Bernardo Fernández; "El caos ambiguo del lugar”, de Gerardo Horacio Porcayo; “Tijuana Express”, de José Luis Ramírez; y "Memoria escindida”, de Rodrigo Pardo.

${ }^{15}$ En este último apartado los relatos representativos son: "Nanografiti”, de Federico Schaffler; "Las tres Fridas”, de Gabriel Trujillo Muñoz; "Radiotechnika cantina”, de Gerardo Sifuentes (1974); y "Soralia”, de Juan Hernández Luna (1962).

Revista Iberoamericana, Vol. LXXVIII, Núms. 238-239, Enero-Junio 2012, $329-348$
ISSN 0034-9631 (Impreso) 
a finales de siglo xx. De esta forma, el relato, al hacer referencia a un hacker, presenta una historia y una visión alternativa del reajuste político y económico neoliberal desde el discurso del uso de la tecnología. En este sentido, el relato sugiere que en México, a finales de siglo xx, empieza a desarrollarse una importante circulación de equipo y servicios computacionales por medio de la integración del mercado mexicano a la economía global. Por una parte, la narración del cuento a través de un adolescente autodidacta en computación, postula que ni la sociedad en general ni las instituciones educativas están preparadas para atender o canalizar las necesidades y las aptitudes de esta generación de jóvenes por medio de un sistema educativo propicio. El cuento sugiere que esto crea un problema para el sistema ya que el protagonista, al ser autodidacta, desarrolla una conciencia que no está controlada por la ideología o las reglas de las instituciones tradicionales. De esta forma, las representaciones en torno a la familia, la educación, el trabajo y la justicia como medios ideológicos que sostienen la unidad nacional son desmoronados y parodiados en el cuento por un adolescente que maneja la computadora y las redes más allá de las capacidades promedio de un profesional en sistemas.

Por una parte, el relato denuncia las tácticas de corrupción gubernamental, el narcotráfico y la delincuencia de cuello blanco desde una perspectiva novedosa: el uso de la tecnología por parte de grupos delictivos para adelantarse a la lucha anticrimen de agencias de investigación como la Procuraduría General de la República (PGR), la DEA y la CIA. Por otra parte, en "El trozo más grande” se insinúa que las habilidades técnicas del hacker son aprovechadas y utilizadas como una herramienta desechable por un poderoso capo de la droga. En este sentido, el relato plantea la idea que grupos delictivos se encuentran tecnológicamente actualizados y a la vanguardia mientras las instituciones nacionales que se encargan de procurar seguridad y justicia se encuentran sumergidas en un estado de oscurantismo tecnológico. Igualmente, el relato funciona como una áspera critica social en el sentido que denuncia la imposibilidad de la juventud de tener derecho a un futuro digno fuera de las diferentes versiones de la economía informal. En este renglón, para el personaje principal del relato, la invitación de trabajar para el narcotráfico resulta ser la única opción de superación económica, de emancipación personal y de tener acceso a un equipo tecnológico sofisticado. El relato concluye advirtiendo que el hacker, por más hábil e inteligente que sea, en tan peligroso ambiente puede ser ultimado ante cualquier indicio de ineficiencia o traición y ser remplazado por otro hacker como si se tratara de una simple renovación de equipo de cómputo. Este aspecto pone de manifiesto que las instituciones de entrada al siglo xxi han perdido solidez y, por ende, han abandonado a los jóvenes a su suerte ya que no representan ninguna garantía de construcción hacia un futuro prometedor.

El cuento está dividido en seis partes en donde la narración de los eventos se encuentra enmarcada en un periodo de cuatro años que corresponden a la edad de catorce a dieciocho años del protagonista. Igualmente, las seis secuencias que describen al protagonista como hacker, de una sección a otra, van comprimiéndose cada vez más

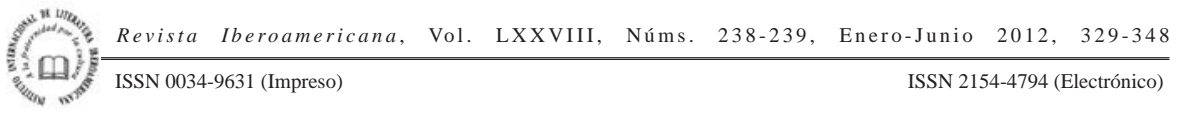


hasta vaciarse de forma precipitada en el trágico desenlace de la historia. El personaje principal del relato, quien se hace llamar "el Grillo", cuenta sus andanzas de hacker organizadas en cuatro tiempos temporales de acción: inicio como hacker autodidacta, consolidación y aceptación en la comunidad hacker, contratación de sus servicios por un narcotraficante y su decisión de delatar las prácticas de su jefe, "El Paisano".

El Grillo es un joven que a causa de la desintegración familiar encuentra una forma de distanciarse y enajenarse del problema entre sus padres a través del uso de una computadora conectada al Internet. El Grillo pronto siente una fascinación por los sistemas de cómputo y la programación y se dedica de tiempo completo a aprender y experimentar por sí mismo todo lo relacionado con la computadora y la red, ya que su escuela era "una mierda" (17). El autoaprendizaje del Grillo se da a pasos acelerados y para probar el desarrollo de sus conocimientos y destrezas empieza a romper sistemas de seguridad de páginas electrónicas. Al principio lo toma como un juego y se infiltra en sistemas de páginas pornográficas, así como en el sistema operativo de su escuela para "cambiar las calificaciones de un cabrón que [lo] cagaba" (17). En poco tiempo el Grillo se convierte en un "pirata informático" con reconocimiento en la comunidad hacker debido a su habilidad de romper complejos sistemas de seguridad de bancos, compañías telefónicas, dependencias del gobierno y corporaciones.

De esta forma, a través de un historial importante y fama de hacker infalible, el Grillo llama la atención y recibe el reto de romper un sistema de seguridad, empresa que acepta sin saber que es una trampa tendida por un narcotraficante para "invitarlo" a trabajar para él. El Grillo no tiene otra opción más que aceptar de forma agradecida el ofrecimiento de "El Paisano", que consistía en ganar mucho dinero por hacer lo que más le gustaba: el hacking. Sus tareas bajo la supervisión del Paisano consistían en la intrusión y el robo de información en cuentas bancarias de otros narcotraficantes y políticos, penetrar los sistemas de seguridad informática de la Procuraduría General de la República (PGR), DEA y CIA para monitorear sus estrategias de acción contra el narcotráfico, así como burlar la seguridad del banco de datos de la Bolsa Mexicana de Valores y Wall Street para plantar información falsa y así hundir imperios económicos enemigos. El excelente trabajo del Grillo lo lleva a acaparar los suficientes medios económicos para abandonar la escuela, independizarse de su disfuncional familia y vivir con lujos. Sin embargo, la relación laboral con su jefe se desgasta cuando la pareja del Grillo muere a causa de una sobredosis de Rancio, droga que El Paisano suministraba periódicamente a la novia del hacker. Como resultado, el Grillo juró vengarse del narcotraficante y para esto acudió a un comandante de la PGR para denunciarlo y tenderle una trampa que llevara a su detención. Sin embargo, el cuento concluye con la muerte y la mutilación del hacker delator.

En términos de estructura, el relato inicia in media res justo en el momento en que el Grillo se encuentra delatando al Paisano. Al empezar el cuento en medio de un diálogo

Revista Iberoamericana, Vol. LXXVIII, Núms. 238-239,
ISSN 0034-9631 (Impreso) 
entre un hacker y comandante en el espacio temporal del presente, se propicia que la presentación del conflicto y los detalles de la atmósfera, así como la caracterización de personajes sean introducidos por un narrador en tercera persona que presenta la información de forma retrospectiva. Este efecto hace que el narrador se mantenga ajeno a proporcionar comentarios personales o ideológicos ya que su participación en el tejido narrativo se lleva a través de la focalización externa o neutra. Norman Friedman se refiere a la focalización externa como el modo dramático ya que estas intervenciones se leen como acotaciones escénicas (Form 155). Al respecto Friedman observa que la importancia del modo dramático como vehículo narrativo "radica mayormente en que el lector, aparentemente, no escucha sino a los personajes mismos, quienes se mueven como en un escenario" (Aspectos 36). Por lo tanto, Friedman agrega que el "ángulo de vista [del lector] es el frente fijo (tercera fila al centro) y la distancia debe ser siempre breve ya que la presentación es totalmente escénica” (Aspectos 36). De esta forma, el narrador se limita a comunicar al lector las circunstancias que han llevado al personaje principal a la situación en la que se encuentra al inicio del relato. En otras palabras, el narrador en ningún momento emite opiniones o comentarios sobre lo que sabe o atestigua, simplemente se ocupa de narrar los hechos anteriores al inicio del relato para poder ubicar al lector en términos de trama, tiempo y espacio, mientras que el personaje principal del relato protagoniza un drama.

La estrategia de iniciar el relato in media res posee la función de establecer un sentido de la inmediatez ya que la analogía que establece Friedman entre ficción y drama tiene el objetivo de crear la ilusión del transcurso del tiempo y de los eventos ante el lector en estado progresivo para que tenga la impresión de encontrarse dentro del mundo narrado. De esta forma, la idea es hacer sentir al lector que lo que acontece en el relato no se encuentra lejos de instalarse en su tiempo y espacio para que considere que las circunstancias que observa en el cuento no se encuentran fuera de la realidad. La trama de "El trozo más grande", al empezar de golpe por medio de la in media res, coloca la historia y al protagonista en el presente, en lo actual y lo inmediato. Así, la trama del cuento, al desenvolverse principalmente en el presente (in media res) y alimentarse de información en el pasado (retrospección), necesita de alguna forma saltar hacia el futuro para anticipar lo que se avecina en la acción.

Un aspecto interesante de "El trozo más grande” es que al estar estructurado en un presente altamente dramatizado utiliza en un mínimo la anticipación. Durante la lectura del texto esto provoca en el lector un estado de incertidumbre y tensión en cuanto a que no se puede deducir hacia dónde se dirige la historia. Inclusive el mismo título del relato añade a esta aporía narrativa, ya que en general no funciona ni como gancho o referencia de la trama ni como medio de anticipación al desenlace. Durante todo el desarrollo del relato el título se mantiene flotando y desligado de los acontecimientos narrados. Es hasta la última línea del texto que se puede crear una conexión definitiva

\footnotetext{
Revista Iberoamericana, Vol. LXXVIII, Núms. 238-239, Enero-Junio 2012, 329-348 ISSN 0034-9631 (Impreso) 
entre título y texto ya que "El trozo más grande" hace referencia a la total mutilación del cuerpo que sufre el hacker por su traición. Mediante esta operación, el autor logra causar un efecto de sorpresa aunado con el cierre fatal del cuento. El intento de anticipación hacia el futuro, así, queda totalmente suspendido y se crea una estrategia narrativa en donde el autor logra que el lector quede atrapado por falta de información, referencias o signos que lo conduzcan a descifrar qué es lo que va a pasar en el cuento. De esta forma, el relato tiene la capacidad de cancelar la imaginación de los lectores con el objetivo de que no puedan deducir la lógica del relato y su conclusión. En otras palabras, el lector está atrapado en la estructura narrativa de la comunicación de masas en donde el pensar no es importante, sino que lo primordial es entregarse al drama y al placer de un desenlace sorpresivo.

Se puede decir que el uso de la in media res no es en lo absoluto una estrategia narrativa novedosa. Sin embargo, Per Aage Brandt estipula que es la estructura semiótica de la comunicación de masas por excelencia con la cual los medios de comunicación se abastecen para ofrecer la vida tal y como se presenta realmente, in media res (12). Por lo consiguiente, en el caso del relato "El trozo más grande”, de Bernardo Fernández, es primordial hacer notar su uso y sus alcances porque, además de ser escritor de CF, él cuenta con una reconocida y amplia trayectoria como diseñador gráfico y caricaturista de historietas. Esta importante experiencia en la industria de la publicidad y del comic hacen de Bernardo Fernández un conocedor y experto de las técnicas más eficaces para transmitir un mensaje de alcance masivo. Por ende, la decisión de BEF por empezar el relato "El trozo más grande" a la mitad de la historia, como en una historieta, tiene una función que trasciende concepciones de estilo o de recurso narrativo.

Bernardo Fernández, dentro del cyberpunk mexicano, representa la cabeza de una segunda promoción de escritores que se unieron al movimiento a mediados de los años noventa con una agenda totalmente diferente a sus predecesores. Una de las características de la primera promoción de escritores de cyberpunk, surgidos del premio Puebla en los ochenta, fue la de colocar el género dentro del mapa de una literatura bien hecha mediante un quehacer literario de calidad y oficio para romper con el estigma de la CF como una literatura light. Así, escritores pioneros del cyberpunk mexicano como Gerardo Porcayo y José Luis Zárate fueron la punta de lanza de esta promoción que se dio la ardua tarea de buscar el reconocimiento literario dentro de la república de las letras a través de la CF. A diferencia de la primera promoción, los escritores que se unieron al movimiento durante los noventa provenían del mundo de la contracultura dark y del universo de los fanzines y con ellos trajeron una orientación distinta a este género literario en sus formas de percibirlo, escribirlo y promoverlo (Trujillo Muñoz, Los confines 353).

En cuanto al estilo, la primera promoción en su labor de creación literaria conscientemente utilizaba técnicas narrativas con el objetivo de lograr textos de densidad y complejidad literaria. Sin embargo, la segunda promoción no se encuentra

\footnotetext{
Revista Iberoamericana, Vol. LXXVIII, Núms. 238-239, Enero-Junio 2012, 329-348 ISSN 0034-9631 (Impreso) ISSN 2154-4794 (Electrónico)
} 
tan preocupada por utilizar mecanismos literarios con el fin de ser reconocidos como artistas, sino que utilizan técnicas literarias o de las ciencias de la comunicación con el simple objetivo de transmitir un mensaje de forma eficiente. Como lo estipula Umberto Eco, en la era de la comunicación de masas se ha borrado la división entre la alta y la baja cultura y el que emite un mensaje no pretende que el que lo reciba lo interprete como obra de arte ya que "[...] no quiere que los elementos tomados en préstamo a la vanguardia artística sean visibles y gozables como tales. Los utiliza sólo porque los ha considerado funcionales" (94).

En este sentido, la crítica en torno a la obra de Bernardo Fernández ha acertado en exaltar la excelente confección de las estructuras narrativas utilizadas por BEF. Por ejemplo, Pepe Rojo ha advertido que la narrativa de Fernández está confeccionada “con la elegancia y economía de un buen diseñador gráfico" (citado por Trujillo Muñoz, Los confines 296). De igual forma, Andrea Bell observa que la obra de BEF se caracteriza por seguir una secuencia intensamente visual por medio de una narrativa de diseño gráfico ("Bernardo Fernández" 80). Las observaciones de Rojo como las de Bell son sumamente útiles para ir identificando los pasajes del cuento en donde se hace evidente la presentación de escenas de alto contenido visual y gráfico, lo que permite apuntar que las bien logradas estructuras narrativas de BEF se encuentran concebidas desde la perspectiva de la comunicación de masas.

El diseño de "El trozo más grande", al abrir de golpe la acción por medio de la in media res, logra rápidamente hacer una fusión exacta entre las estructuras de la alta y de la baja cultura desde la CF que pasa totalmente desapercibida a través de un relato en real time. El uso estilístico de la in media res sutilmente introduce al personaje principal en una situación de inmediatez y de límite como si estuviera desenvolviéndose dentro de los parámetros de un reality show altamente dramatizado para captar la atención del lector de forma instantánea, como si se tratara de un programa de televisión. En este sentido, BEF no solamente logra confeccionar un relato altamente estilizado, en cuestión de estructura, sino que también consigue dibujar una secuencia altamente visual. De esta forma, al utilizar el recurso de la in media res, Fernández ofrece a sus lectores una sutura invisible entre el goce del texto y el goce de la imagen en donde se fusionan técnicas narrativas y cinematográficas para dar vida a una especia de relato literario-gráfico que se desenvuelve en tiempo real.

Se puede decir que Bernardo Fernández, desde el inicio de "El trozo más grande", logra colocar la trama, a los personajes y a sus lectores dentro de la incesante experiencia de un reality show en donde un aspecto de la vida de México, a finales de siglo xx, se representa "en directo". Esto a través de los personajes inmiscuidos en el drama en donde un segundo narrador en "modo-cámara", que a diferencia del narrador en "modo dramático”, será el que se encargará de brindarle un efecto visual al relato literario. Como se mencionó anteriormente, al iniciar el relato in media res y desarrollarse en el presente necesita un vehículo narrativo que se encargue de presentar el conflicto, los

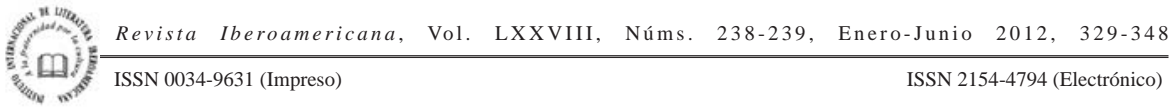


detalles de atmósfera, así como la caracterización de personajes y las circunstancias que han llevado a los personajes al lugar en donde se encuentran. Este narrador en "modo dramático", por lo tanto, se limita a proporcionar información en forma de acotaciones para que el lector se pueda situar en el relato. En contraste, el narrador "modo-cámara" tiene una función de enunciación mucho más visual que lingüística. Esta diferencia entre lo visual y lo lingüístico es lo que proporciona la oportunidad de intuir y notar las intervenciones de los dos tipos de narradores. Mientras las intervenciones del narrador en "modo dramático" tienden a ser unidimensionales y estáticas al llevarse a cabo en un solo plano o encuadre, las enunciaciones del narrador en "modo cámara” se caracterizan por su calidad dimensional debido a sus diferentes maniobras de movilidad.

Esto se puede observar claramente después de un diálogo entre el hacker y el comandante de la PGR donde el Grillo se encuentra relatando cómo fue que se involucró en el narcotráfico y menciona el nombre de su jefe, El Paisano. Inmediatamente a continuación se interrumpe el relato del Grillo y aparecen el narrador en "modo dramático” y “modo cámara” para describir en formato lingüístico y visual lo que acontece en la historia.

Una onda fría recorrió la espalda del capitán Tapia. En sus ojos se encendió un fulgor que no pasó desapercibido por el Grillo. ¡El Paisano! Uno de los malandros más buscados al norte del país. Miembro renegado de un cártel sinoalense, había decidido apartarse de la mancuerna de autoridades-narcos [...] Despreciando la protección ofrecida por los altos funcionarios que aceptaban otros capos, se había convertido en un outsider que se movía al margen de las bien organizadas redes del narcotráfico; tanto la policía como sus ex-socios deseaban verlo fuera del negocio. (18)

Como se puede observar, las primeras dos oraciones de la referencia anterior pertenecen al narrador en "modo cámara” ya que son sumamente visuales. La primera oración equivale a un primer encuadre que en términos cinematográficos podríamos describir como en subjetivo ya que el narrador en "modo cámara" se encuentra colocado detrás del comandante, lo que le permite registrar el sobresalto del comandante desde su espalda. Mientras tanto, la segunda oración resulta significativamente interesante porque el narrador en "modo cámara" ha dado un giro de ciento ochenta grados para pocionarse en frente de Tapia y por medio de un close up muestra los ojos encendidos del comandante. Sin embargo, la misma escena es extendida hacia una segunda acción por medio del montaje para yuxtaponer dos imágenes diferentes en donde ahora el narrador en "modo cámara" ha vuelto a girar, pero en esta ocasión para focalizar la expresión facial del hacker que denota que ha percibido el sobresalto del agente judicial. En contraste, después de estos dos encuadres iniciales el narrador en "modo dramático" aparece para enunciar, mediante una especie de voz en off, información descriptiva que será de suma utilidad para que el lector se informe sobre quién es El Paisano. El efecto de esta intervención en "modo dramático" parece colocar el desarrollo de la acción en

\footnotetext{
(3) Revista Iberoamericana, Vol. LXXVIII, Núms. 238-239, Enero-Junio 2012, 329-348 ISSN 0034-9631 (Impreso) ISSN 2154-4794 (Electrónico)
} 
un estado de pausa para después reiniciarse en el presente narrativo justo en donde se había suspendido el relato.

La participación lingüística del narrador en "modo dramático", en forma de acotaciones y la colaboración visual del narrador en "modo cámara" a través de una secuencia de imágenes, postula que el relato literario de Bernardo Fernández, además de enriquecerse con elementos cinematográficos también se encuentra relevantemente emparentado con la estructura de la historieta. Peter Bondanella asevera que el comic strip alimenta su formato narrativo por medio de elementos cinematográficos ya que "codified syntax of frame composition, and relationship between one frame and the next often contains a montage similar to that employed by cinema” (55). Sin embargo, si “El trozo más grande”, como se ha propuesto, se enfila hacia el género del reality show en donde todo se muestra en real time, entonces el cuento no utiliza técnicas mecánicas de manipulación de imágenes como en el cine clásico, sino que se organiza a manera de una edición digital en video.

Esta diferencia es importante ya que la concepción del cine clásico, desde una perspectiva ideológica determinada, intenta hacer una selección de imágenes para proyectar una determinada concepción de la realidad. Per Aage Brandt asegura que el uso del video en el reality show tiene el objetivo de mostrar cómo "los humanos tienen que soportarse vistos como son, como actúan 'realmente', fuera de toda redacción, fuera de control o del filtro eisensteiniano", ya que la nueva tecnología como "la videoscopía de transmisión directa empequeñece, desmitifica y reduce la representación de lo humano" (15). En otras palabras, se puede decir que el relato de Bernardo Fernández, además de utilizar una estructura perteneciente a la historieta y al cine/video para constituir la secuencia narrativa, igualmente se vale del comic y el reality show para caracterizar a sus personajes y así mostrar al hacker, al narcotraficante y al comandante como figuras caricaturizadas y animadas con el propósito de hacer una parodia violenta y de humor negro de tres participantes activos del quehacer social mexicano.

La caracterización de los tres personajes principales se llevará a cabo a través de la focalización del hacker quien se describirá a sí mismo, como también al comandante y al narcotraficante desde la visión de un joven inmaduro que tiene acceso y que puede desenvolverse bajo las tecnologías de la comunicación y la información en un México al borde del siglo xxı. Mediante estas intervenciones descriptivas del Grillo se podrá observar que la conciencia, la experiencia, la relación y la concepción del mundo del hacker se encuentra totalmente regida como si él observara la vida desde la lectura de una revista de celebridades, como si se desenvolviera en una historieta o como si se encontrara dentro de un videojuego. Por ejemplo, a través del relato se puede observar cómo el Grillo asume su corta vida como si estuviera en "un cuento de hadas pachecas" (25) y describe su personalidad bajo el estereotipo de un Unix-nerd (18) que logra realizar vedadas fantasías al estilo de la serie The Revenge of the Nerds. De forma similar, el hacker se refiere a su vida amorosa "como un cómic de Archie: el nerdo y la reina de

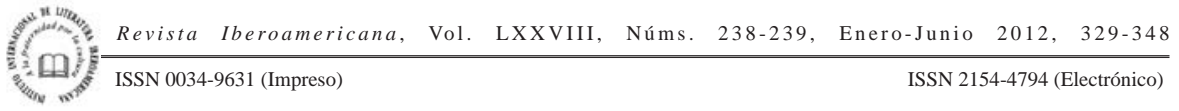


belleza” (26). En cuanto a su visión de espacios y personas, también se manifiesta con una marcada mediación por artículos de consumo visual. El Grillo, al referirse a su primera reunión con El Paisano, describe que el lugar de la cita estaba concurrido por “actores, cantantes, hijos de alguien, políticos, rostros familiares de las revistas” y que “parecían salidos de 'The Face’” (21). Al caracterizar al tecno-narco dice:

[...] me encontré con unos lentes de espejo que cubrían la mirada de un hombre [...] que rondaría los 45 años, muy alto, su cara iba adornada de un bigotazo y grandes patillas; llevaba un sombrero texano del que escapaban mechones a la rasta, y ropa de neopreno, con una chamarra vaquera de piel de jirafa [...] Disfrutaba pensar en el Paisano como un Darth Vader nacido en Mocorito. (23)

Por una parte, las citas anteriores por medio de la imaginación y el lenguaje de un niño-adolescente inmaduro contribuyen para afirmar que la ideología y la identidad del personaje principal se encuentran regidas desde la caracterización de personajes y atmósferas de historieta. Esto conlleva a proponer que el hacker es una metáfora de la nación que muestra al país en proceso de avance tecnológico, pero que en su estructura social y política se mantiene sumamente atrasado ya que el conocimiento técnico sin una infraestructura y una educación adecuada conlleva a un conocimiento equivocado y a un uso indebido de la tecnología. En este renglón, Andrea Bell observa que Bernardo Fernandez "reflects a fairly prevalent attitude in contemporary Mexican science fiction about the modern computer age-that is, that for all its benefits, digital technology represents a beguiling, insidious treat to personal identity, security, and agency” (81). De esta forma, el hacker en el cuento funciona como una alegoría nacional que muestra las contradicciones entre la híper-modernidad y el subdesarrollo durante la era de la información en México. La tecnología en el cuento se convierte en una mera herramienta de entretenimiento y ocio que arroja como resultado que el uso de la computadora y la red se perfile en un juego de niños y adolescentes.

Por otro lado, la caracterización del hacker como un niño-adolescente, la imagen del narcotraficante como exótico, la representación del agente judicial como ignorante y el retrato de personas y atmósferas como salidos de una revista de celebridades tienen como común denominador un aire de historieta en donde las pinceladas descriptivas son grotescas y desproporcionadas. Tanto el hacker como el judicial y el narcotraficante son bufones deshumanizados -y por lo tanto desfigurados-en el reality show del desempleo, de la inseguridad, de la violencia y la inoperatividad que afecta a la nación. "El trozo más grande”, de esta manera, logra ridiculizar y parodiar las instituciones, los discursos y los personajes que mantienen la unidad de lo nacional al borde del colapso y el caos. El relato bajo su estructura en real time por medio de la in media res logra captar (en el acto) lo penoso y lo desastroso de un México en donde nadie sobrevive a la catástrofe económica si no se alinea o busca salvación en el mercado de la economía informal

Revista Iberoamericana, Vol. LXXVIII, Núms. 238-239, Enero-Junio 2012, $329-348$
ISSN 0034-9631 (Impreso) 
en donde una posibilidad son los "oficios" del narcotráfico. Por lo tanto, en el cuento -así como la realidad en directo a la que alude- el único personaje que se perfila como regulador de la debacle nacional es el (tecno)narco.

Culturalmente, el género del cyberpunk muestra un cambio en el paradigma de la estructura social/política debido a la introducción o al uso de las tecnologías de la comunicación y la información, pero lo interesante es que BEF no solamente utiliza el género del cyberpunk en su fórmula anglosajona, sino que renueva el cyberpunk a través de la añadidura de una realidad sumamente presente, y hasta cierto punto ya cotidiana o normalizada, de la vida diaria del México contemporáneo: la narcocultura. El hacker alineado a las prácticas de los carteles del narcotráfico es una variante que en la tradición del género escrito en inglés no se presenta. La realidad de México y su estrecha relación con la cultura del narcotráfico hacen que el contexto del cuento y la anécdota contada sean creíbles para el lector. Esta receta de credibilidad hace que el cyberpunk en México no sea una copia a papel carbón, sino una reformulación temática del género a la mexicana.

\section{BiBLIOGRAFÍA}

Álvarez, Jorge Eduardo. “Cenizas de fractal”. 9·9·99 Cuentos de ciencia-ficción, fantasía y horror. Tamaulipas: Taller Literario Tierra Ignota, 1999. 15-24.

Arquilla, John y David F. Ronfeldt. Networks and Netwars: The Future of Terror, Crime, and Militancy. Santa Monica: Rand, 2001.

Ávila, Isidro. “La red”. Más allá de lo imaginado. Vol. 2. Federico Schaffler, ed. México: Tierra Adentro, 1991. 137-48.

Bell, Andrea. "Bernardo Fernández Brigada”. Latin American Science Fiction Writers: An A-to-Z Guide. Darrell Lockhart, ed. Connecticut: Greenwood Press, 2004. 7981.

Bondanella, Peter. Umberto Eco and the Open Text: Semiotics, Fiction, Popular Culture. Nueva York: Cambridge UP, 1997.

Brandt, Per Aage. In media res: La estructura semiótica de la comunicación de masas. Valencia: Universidad de Valencia, 1995.

Castells, Manuel. “Informacionalismo y la sociedad red”. Epílogo. La ética del hacker y el espíritu de la era de la información. Pekka Himanen. Barcelona: Destino, 2001. 169-91.

Chavarría, Héctor. “Lo último de nuestras vidas”. Los mapas del caos: Breve antología de ciencia-ficción mexicana. Gerardo Porcayo, comp. México: Ramón Llaca/ Universidad Autónoma de Tlaxcala, 1997. 5-9.

Chípuli Padrón, Jorge. “Panchito’s story”. Silicio en la memoria: Antología cyberpunk. Gerardo Porcayo, comp. México: Ramón Llaca, 1998. 110-8.

Eco, Umberto. Apocalípticos e integrados. México: Tusquets, 2003.

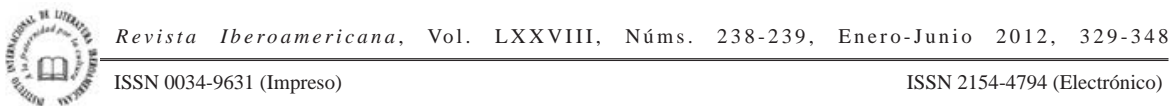


Fernández, Bernardo. "Sólo se recuerda el primero”. Bzzzzzzt!! Ciudad interfase. México: Times, 1988. 33-41.

"El trozo más grande” Silicio en la memoria: Antología cyberpunk. Gerardo Porcayo, comp. México: Ramón Llaca, 1998. 13-32.

“Elúltimo de los hackers”. Bzzzzzzt!! Ciudad interfase. México:Times, 1998.71-6. "Wonderama”. Bzzzzzzt!! Ciudad interfase. México: Times, 1988. 9-21.

Fernández, Bernardo y Gerardo Sifuentes. “(e)”. Visiones periféricas: Antología de la ciencia ficción mexicana. Miguel Ángel Fernández, comp. Buenos Aires: Lumen, 2001. 173-86.

Fernandez, Miguel Ángel. "Más allá de lo imaginado: La antología que hizo historia". Ciencia ficción mexicana. 2005. <http://www.ciencia ficcion.com. $\mathrm{mx} /$ ?uid=2\&cve=11:06>. 11 julio 2009.

Friedman, Norman. Aspectos de la novela moderna. Montevideo: Fundación de Cultura Universitaria, 1973.

Form and Meaning in Fiction. Athens: U of Georgia P, 1975.

González, Andrés. "Virtual realidad”. Umbrales: Revista mexicana de ciencia-ficción, fantasía y horror 10 (nov.-dic. 1994): 30.

Hernández Luna, Juan. “Soralia”. Silicio en la memoria: Antología cyberpunk. Gerardo Porcayo, comp. México: Ramón Llaca, 1998. 90-101.

Heuser, Sabine. Virtual Geographies: Cyberpunk at the Intersection of the Postmodern and Science Fiction. Amsterdam: Rodopi, 2003.

Ilich, Fran. "Hackers Chat: Interview with X-Ploit About Attacks on Mexican gvt". Politech: Politics and Technology. <www.politechbot.com/p-01254.html>. 10 enero 2009.

Kellner, Douglas. Media Culture: Cultural Studies, Identity and Politics between the Modern and the Postmodern. Londres: Routledge, 1995.

Kuri, Caín. "Mercurio rojo”. Cuentos compactos cyberpunk. Puebla: La langosta se ha posado/Fractal 'zine, 1997. s. pag.

"Ciudad Perdida". Silicio en la memoria: antología cyberpunk. Gerardo Porcayo, comp. México: Ramón Llaca, 1998. 103-7.

Lavín, Guillermo. "Llegar a la orilla”. Bajo el signo de Alpha: Antología. Tamaulipas: Libro Digital, 2000. 91-106.

Lizama, Jorge Alberto. "El poder de las redes sociales: activismo vs páginas web del gobierno mexicano". La cultura del espectáculo y el escándalo: Los media en la sociedad actual. Nery Córdova, coord. México: Universidad Autónoma de Sinaloa. 3-20.

"Hackers México, del Hack-Zapatismo a Raza Mexicana”. Comunicación cybermedios: sociedad digital, cibercultura y cyberpunk. 5 oct. 2006. <http:// comunicacion.cybermedios.org/?p=138>. 21 sept. 2009.

Revista Iberoamericana, Vol. LXXVIII, Núms. 238-239,
ISSN 0034-9631 (Impreso) 
"La Internet, potencialmente socializadora: Alberto Lizama”. La Jornada. 16 oct. 2007. <http://www.jornada.unam.mx/2007/1/16/index.php?section=espectac ulos\&article=a10n1esp $>$. 25 oct. 2011.

Limón, Carlos Alberto. “Tajamar neutral”. Silicio en la memoria: Antología cyberpunk. Gerardo Porcayo, comp. México: Ramón Llaca, 1998. 48-61.

Meikle, Graham. Future Active: Media Activism and the Internet. Annandale, N.S.W.: Pluto Press, 2002.

Melchor, Alejandro. "La noche del cazador”. Umbrales: Revista mexicana de cienciaficción, fantasía y horror 10 (nov.-dic. 1994): 18-9.

Moreno, Horacio. Cyberpunk: Más allá de Matrix. Barcelona: Círculo Latino, 2003.

Pardo Fernández, Rodrigo. “El navegante”. Silicio en la memoria: Antología cyberpunk. Gerardo Porcayo, comp. México: Ramón Llaca, 1998.134-47.

"Memoria escindida”. El hombre en las dos puertas: un tributo de la cienciaficción mexicana a Philip K. Dick. Gerardo Porcayo, comp. México: Lectorum, 2001. 58-65.

Pitma, Thea. "Latin American Cyberprotest: Before and After the Zapatistas”. Latin American Cyberculture and Cyberliterature. Claire Taylor y Thea Pitman, eds. Liverpool: Liverpool UP, 2007.

Porcayo, Gerardo. La primera calle de la soledad. México: Fondo Editorial Tierra Adentro, 1993.

La primera calle de la soledad. México: Vid, 1997.

“Imágenes rotas, sueños de herrumbre”. Umbrales: Revista mexicana de ciencia ficción, fantasía y horror 10 (nov.-dic. 1994): 7-9.

“El caos ambiguo del lugar”. Visiones periféricas: antología de la ciencia-ficción mexicana. Miguel Ángel Fernández, comp. Buenos Aires: Lumen, 2001. 164-70.

“Cyberpunk, ciencia- ficción y thriller”. Umbrales: Revista mexicana de ciencia ficción, fantasía y horror 4 (otoño 1993): 3-5.

“El cyberpunk”. Umbrales: Revista mexicana de ciencia-ficción, fantasía y horror 33 (sept. 1997): 2-3.

Ramírez, José Luis. “Cyberpunk: El movimiento en México”. Ciencia-Ficción mexicana. 2005. México. <www.ciencia-ficcion.com.mx/?uid=2\&cve=11:09> 11 jul. 2009.

“Dos días de permiso”. Los mapas del caos: breve antología de ciencia-ficción mexicana. Gerardo Porcayo, comp. México: Ramón Llaca/Universidad Autónoma de Tlaxcala, 1997. 39-41.

"Hielo". Visiones periféricas: antología de la ciencia- ficción mexicana. Miguel Ángel Fernández, comp. Buenos Aires: Grupo Editorial Lumen, 2001. 202-219. “Santo Sudario”. Silicio en la memoria: Antología cyberpunk. México: Ramón Llaca, 1998. 34-45.

\footnotetext{
Revista Iberoamericana, Vol. LXXVIII, Núms. 238-239, Enero-Junio 2012, 329-348 ISSN 0034-9631 (Impreso) ISSN 2154-4794 (Electrónico)
} 
“Tijuana express”. Cuentos compactos cyberpunk. Puebla: La langosta se ha posado/Fractal 'zine, 1997. sin paginación.

Rojo, Pepe. “Conversaciones con Yoni Rei”. Visiones periféricas: Antología de la ciencia ficción mexicana. Miguel Ángel Fernández, comp. Buenos Aires: Lumen, 2001. 188-99.

“Para-Skim”. Silicio en la memoria: Antología cyberpunk. Gerardo Porcayo, comp. México: Ramón Llaca, 1998. 64-77.

Ruido Gris. México: Universidad Autónoma Metropolitana, 1996.

Schaffler, Federico, ed. Más allá de los imaginado. 3 vols. México: Tierra Adentro, 1991-94.

“Nanograffiti”. Umbrales: Revista mexicana de ciencia-ficción, fantasía y horror 10 (nov.-dic. 1994): 10-3.

Sifuentes Marín, Gerardo. “Cybersexo”. Más allá de lo imaginado III. Federico Schaffler, ed. México: Fondo Editorial Tierra Adentro, 1994. 171-82.

“El epílogo de Alicia”. Umbrales: Revista mexicana de ciencia ficción, fantasía y horror 10 (nov.-dic. 1994): 16-7.

"Persiana de piel”. Cuentos compactos cyberpunk. Puebla: La langosta se ha posado / Fractal 'zine, 1997. s. pag.

Trujillo Muñoz, Gabriel. Los confines: Crónica de la ciencia-ficción mexicana. México: Vid, 1999.

"Futuro bajo palabra”. Tierra Adentro 14 (feb.-mar. 2002): 44-52.

El futuro en llamas: cuentos clásicos de ciencia- ficción mexicana. México: Vid, 1997.

“Las tres Fridas”. El hombre en las dos puertas: un tributo de la ciencia- ficción mexicana a Philip K. Dick. Gerardo Porcayo, comp. México: Lectorum, 2000. 231-52.

Velarde, José Luis. “Los crímenes que conmovieron al mundo”. Bajo el signo de Alpha. Tamaulipas: Libro Digital, 2000. 151-6.

Yehya, Naief. Los sueños mecánicos de las ovejas electrónicas: el cyberpunk en el cine. México: Nitrato de Plata, 1994.

Zárate, José Luis. “Análogos y Therblings. Hyperia. México: Lectorum, 1999. 141-50. “Cajas chinas”. Hyperia. México: Lectorum, 1999. 93-7.

“Hyperia”. Hyperia. México: Lectorum, 1999. 73-88.

Revista Iberoamericana, Vol. LXXVIII, Núms. 238-239, Enero-Junio 2012, 329-348
ISSN 0034-9631 (Impreso) 